\title{
Danger Detection during Fight against Compartment-Fire Using Moving Averages in Temperature Recordings
}

\author{
Michel Lebey, Amal Bouaoud, Eloi Lambert \\ Laboratoire Ondes et Milieux Complexes (LOMC, UMR CNRS 6294), University of Le Havre, Le Havre, France \\ Email: michel.lebey@univ-lehavre.fr, amal.bouaoud@univ-lehavre.fr, eloi.lambert@univ-rouen.fr
}

Received June 2014

\begin{abstract}
In compartment fires (houses, buildings, underground, warehouse, etc.), smokes are a major danger during firemen intervention. Most of the time, they are at high temperature $\left(>800^{\circ} \mathrm{C}\right)$ and they flow everywhere through many kinds of ducts, which leads to the propagation of the combustion by the creation other fires in places which may be far away from the initial fire. In this paper, we present a new approach of the problem, which allows to better follow the fire behavior and especially to detect the dangers that may appear and endanger firefighters. This approach consists in a mathematical analysis based on the comparison of moving averages centered in the past, calculated on the temperature recordings of the smokes. As a consequence, this method may allow to improve decision support in real time and therefore to improve the security and the efficiency of firefighters in their operations against that kind of fires.
\end{abstract}

\section{Keywords}

Compartment Fire, Decision Support in Real Time, Moving Average, Danger Detection

\section{Introduction}

In firefighting, knowledge of fire dynamics and hazards would allow building better decision supports. This can be done by developing the ability to obtain physical measurements which are specific to the fire and to be able to transmit them outside to a control centre and analyse them in order to have a more precise assessment of the situation and consequently to improve decision supports. Moreover, this may help to improve the global organization of firefighting departments.

From a physical point of view, the spread of a fire can occur in three ways: conduction, convection and radiation. The transition from a growing fire to a widespread fire can take many forms. But one of the most important in compartment fires is the propagation of the fire by the smokes, because of their mobility associated to their high temperature (often higher than $800^{\circ} \mathrm{C}$ ), e.g. they can move everywhere through any type of duct such as corridors, staircases, rows of rooms, but also through technical ducts such as elevator shafts, ventilation and conditioning-air ducts, etc. When they are drawn into a non-burning space, even far away from the start of the 
fire, an auto-ignition may occur if they are mixed with the oxygen in air, or they may ignite another fuel of low auto-ignition such as for instance paper, cardboard, or wood. This situation leads to the extension of the fire throughout the whole building. In operation, ventilation in fire using portable fans can help to draw them outside and so to protect firefighters. Many studies have been carried out on this subject in different situations, such as Fire Ventilation [1], ventilation in compartment fire [2], in tunnels [3], ventilation in rooms on fire [4] or in an underground station [5].

On the other hand, if smokes are a major hazard in compartment firefighting and thus remain to be studied, they are, however, of major interest because they contain and convey a certain amount of information (temperature, pressure, speed, physical composition and chemical) corresponding to the fire, its nature, its evolution and its risks.

In the first part of this study, we show how it is possible to get precise information about the fire and its evolution, and about the efficiency of the strategies employed to fight it. In the second part, we show how it is possible to detect the dangers that may occur by the use of the comparison of two moving averages in the past calculated in a temperature recording. At the end, we show how this comparison of averages in the past may allow to improve decision support in real time and therefore may allow to improve the security and the efficiency of firefighters in their operations against compartment fires. Moving averages are often used in other fields such as Energy [6], Knowledge-Based Systems [7], and Procedia Technology [8].

\section{Follow-Up of Temperatures in the Development of Fire and of the Effectiveness of Strategies Put in Place to Fight against Fire}

The demonstration of the use of the temperature recording analysis in order to follow the evolution of the fire and the effects of the means used to fight it, has been made with an experiment of a simulation of a fire in real conditions. This experiment has been made in hospital room, $6 \mathrm{~m}$ long, $5 \mathrm{~m}$ wide and $3 \mathrm{~m}$ high, in which there was about $300 \mathrm{~kg}$ of combustibles: a table and a chair made of wood, an armchair made of imitation leather, a wardrobe full of clothes, another table with a computer and a TV, and two beds with blankets. Temperatures were recorded at different locations as shown on Figure 1. Temperatures were measured at different locations as shown on Figure 1, using K thermocouples and recorded and analysed with the LabView software.

In this experiment, the fire intervention began about 5 minutes after the fire start. This lapse of time ( 5 minutes) represents the mean usual time between the alert and the arrival of the firefighters on the spot. The fire attack was made using two portable fans only, without water hose at the beginning, in order to show the effects of directed air flows on the smoke movement control. Obviously, in a real situation, the attack would have been made using a water hose at the same time.

The temperature curves shown on Figure 2 are significant of the obtained results. In the first stage without any action, a temperature plateau appears at about $550^{\circ} \mathrm{C}$. This is the temperature of auto-ignition of carbon monoxide, a gas contained in great amount in the smoke of compartment fires. Just after this plateau a sudden global temperature rise occurs to a level higher than $800^{\circ} \mathrm{C}$. This phenomenon is named the flashover, wellknown by firefighters because it is very dangerous, even fatal. On Figure B, the vertical V1 indicates the start of the first fan, which produces a global temperature decrease. This is due to two reasons. Firstly, the glass window had exploded under the effect of the heat. Secondly, the fan located in front of the front door of the building created an inflow of air, which forced the smokes to be drawn outwards through the broken glass window. Nevertheless, this temperature decrease stopped after a few minutes and was followed by another sudden violent temperature rise because the combustion was reactivated by the oxygen drawn inwards by the air flow. This shows that the fan used is not powerful enough to draw outwards all the smoke produced by the fire. The vertical V2 shows the start of the second fan and from that moment the power of the two fans has become sufficient to force all the smoke to flow outwards and to carry the heat outside.

Two main remarks can be made from this test:

Remark 1: The temperature curve under the ceiling inside the corridor shows the fire's evolution and the effect of the action that was undertaken and the lack of power for the first fan alone, particularly. Finally, it clearly shows the efficiency of the ventilation after the second fan starts when the ventilation has become strong enough. So, a smart sensor set at this location would communicate clear information about the fire's evolution.

Remark 2: Curves B and E clearly show the temperature plateau which occurs just before a flashover, a wellknown dangerous phenomenon which is followed by a drastic temperature rise higher than $800^{\circ} \mathrm{C}$. 




Figure 1. The smoke movement control by ventilation with portable fans; left: details of the experimental situation; right: photo showing the effectiveness of the ventilation in the fire, the flow of combustion gas is discharged to the outside, so the dangers of flashover and spread are much better controlled, the intervention is secured.

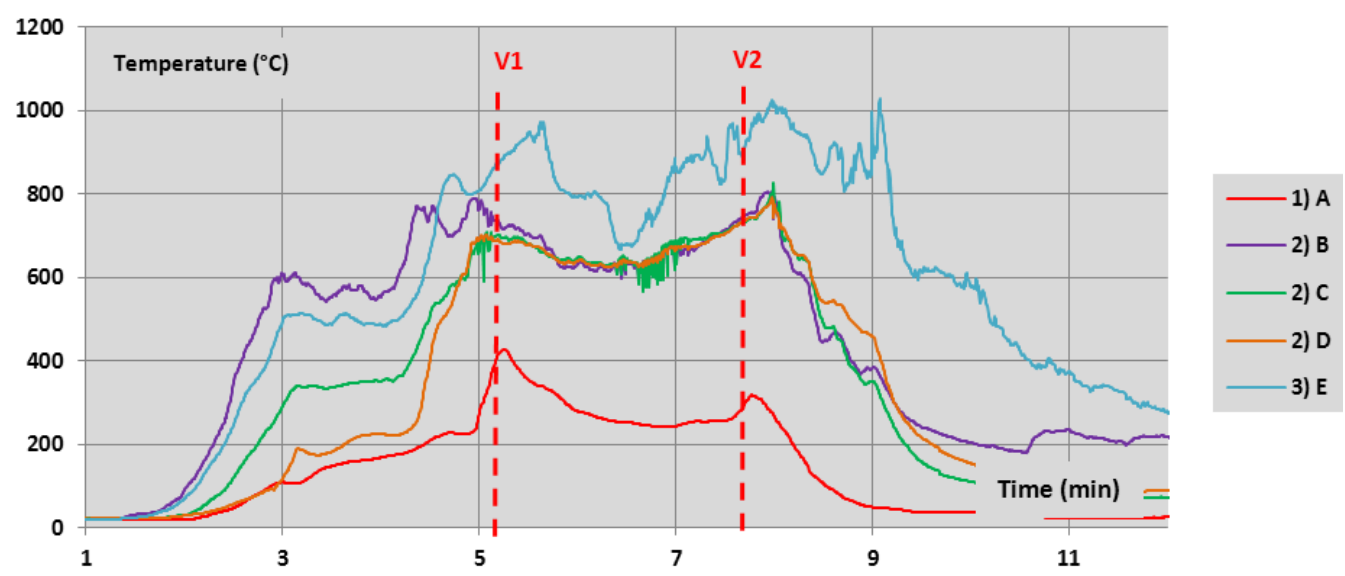

Figure 2. Experiment for ventilation efficiency in firefighting and danger detection: time temperature evolutions all along the test and portable fan start effects. Temperature curves are as follows: 1) A: $20 \mathrm{~cm}$ under the ceiling in the corridor, 2) inside the room on fire just close to the door: $\mathrm{B}, 20 \mathrm{~cm}$ under the ceiling, $\mathrm{C}$ at a height corresponding knees-to-head for a firefighter (which is the progression position into a fire), D, $20 \mathrm{~cm}$ above the floor, and 3) inside the burning room just in front of the glass window: E, 20 $\mathrm{cm}$ under the ceiling and $\mathrm{F}$ at mid height. V1 shows the first fan start and V2 the second fan start.

\section{Risk Anticipation in Firefighting Using Moving Averages in Temperature Recordings}

\subsection{Time Series of Temperatures and Moving Averages Centered in the Past}

In that kind of situation, the temperature recordings can be analysed as temporal series on which it possible to apply laws which allow to detect some events. In severe situations, such as blaze, identifying dangerous events become a way of security to protect firefighters from the dangers of hot smokes which may explode or against the flashover. In this study, only the temperatures are considered knowing that other physical quantities could be use and give more information about the fire and its dangers.

In this analysis we use moving averages centered in the past, calculated as follow:

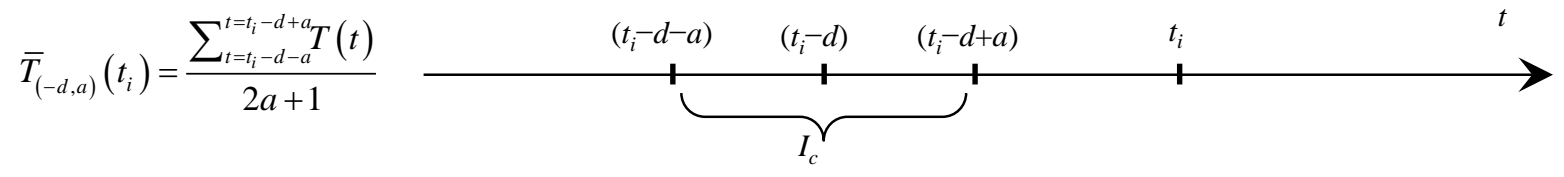


With: $I_{c}$, the interval in which the moving average is calculated, $d$ : the temporal distance in the past, $a$ : the half amplitude of the calculating interval, $t_{i}$ : the date at which the moving average is calculated in the past, and with the following condition: $t_{i}-d+a<t_{i}$.

Through this way it possible to define moving averages centered in the past at a temporal distance $d$. In a simple step, three moving averages could be defined:

- a first one at a short term, such that $t_{i}-d$ is close to $t_{i}$, i.e. $d$ small,

- another at long term, such that $t_{i}-d$ is far from $t_{i}$, i.e. $d$ great,

- at least, an intermediate moving average at a distance $d$ chosen between the two previous.

In this calculation, $a$ and $d$ are parameters that may be chosen in order to obtain the best possible results, as it will show in the analysis of the experiment detailed in the previous section.

\subsection{Prediction of the Events in a Compartment Fire Using Two Moving Averages Centered in the Past}

In this part, the study is carried out with the recording of the temperature under the ceiling close to the door inside the room on fire in the experiment described in the previous section. Two moving averages centered in the past are compared thus two main characteristics can be highlighted:

1) When the evolution of the moving average centred in the past at a long term (d2) crosses the moving average at short term and becomes higher, this means that the temperature is going to decrease, and this means that the power of the fire is going to decrease, and therefore this means that the situation is going to be made safer.

2) When the evolution of the moving average centred in the past at a long term (d2) crosses the moving average at short term and becomes lower, this means that the temperature is going to increase, and this means that the power of the fire is going to increase, and therefore this means that dangers may occur, such as smoke explosion or a flashover.

Figure 3 shows the temperature evolution recorded and two moving averages, one centered at $-15 \mathrm{~s}$ and the other centered at $-30 \mathrm{~s}$. The intersections of the curves of these two moving averages highlight different phases of the fire with specific events:

- From the beginning to A: the moving average at $-15 \mathrm{~s}$ is above the one at $-30 \mathrm{~s}$, this means that the temperatures are increasing, therefore the fire power is increasing,

- at A point, the average at $-15 \mathrm{~s}$ becomes higher than the average at $-30 \mathrm{~s}$, this means that the fire power does not increase any more, which is confirmed by the temperature plateau appearing on the whole temperature recordings,

- between A and B, the temperature plateau, there are oscillations in the curves of both averages, which shows the possible appearing of a flashover because the temperatures are higher than $550^{\circ} \mathrm{C}$, the self-ignition temperature of the $\mathrm{CO}$ gas,

- between $\mathrm{B}$ and $\mathrm{C}$ once again the moving average at $-15 \mathrm{~s}$ becomes lower than the moving average at $-30 \mathrm{~s}$ with a sudden drastic temperature increase, this is the flashover, the well-known dangerous event,

- between $C$ and $D$ point, there are once again oscillations in both averages and temperatures remain quite stable but at a high level, thus the situation remains dangerous,

- at $\mathrm{D}$ point, the average at $-15 \mathrm{~s}$ becomes once again under the average at $-30 \mathrm{~s}$, this means that all temperatures are going to decrease, therefore the situation may become safer, which shows that the ventilation applied seems to be efficient,

- at E point, there are once again a short period of oscillations and then the average at $-15 \mathrm{~s}$ becomes higher than the average at $-30 \mathrm{~s}$, clearly; this event clearly shows that if the first ventilation was efficient at the beginning it becomes insufficient because it brings in fresh air that increases the combustion dynamics without being powerful enough to force all the gas in combustion to flow outward,

- at $\mathrm{F}$ point to $\mathrm{E}$ point, the average at $-15 \mathrm{~s}$ becomes once again lower than the average at -30 , which clearly shows the positive effect of the start of the second fan which increase the ventilation and can force all the gas in combustion to flow outside. All the temperatures inside the room decrease to under $220^{\circ} \mathrm{C}$, therefore the situation is under control and completely secured even if there is a small temperature increase from $\mathrm{E}$ point.

The comparison of the two moving averages centered in the past clearly shows that it is possible to detect events which may be dangerous such as flashover, or to know that the first ventilation is not powerful enough. This information may become very important for the firefighter commander in order to improve its decision capacities in real time. This is possible because all the calculations could have been made in a very short time due 
to the fact that the time distance in the past of each moving average was very short, lower than $30 \mathrm{~s}$.

\subsection{Analysis of the Distance in the Past of the Moving Averages}

In the analysis carried out in the previous section the temporal distances in the past $\mathrm{d} 1$ and $\mathrm{d} 2$ have been chosen in order to obtain significant results. However the question is how to choose the value of these temporal distances in the past and how long time it is necessary to obtain these values. As it was shown in the previous section the delay to obtain one value is very short. In order to analyse this problem, other calculation were also made in the same time with in addition three temporal distances in the past, $\mathrm{d} 1=-15 \mathrm{~s}, \mathrm{~d} 2=-30 \mathrm{~s}, \mathrm{~d} 3=-1 \mathrm{~min}$, $\mathrm{d} 4=-5 \mathrm{~min}$, and d5 $=-10 \mathrm{~min}$. Figure 4 shows the results of these comparisons with the two used in the previous section. It is clear that these latter two moving averages give the best results. Moreover they are calculated with the two shortest times in the past, thus they are useful and completely compatible with the characteristic time of a compartment fire, about 10 minutes to 1 hour.

The moving average at -1 min gives also useful information when it is compared to that at $-30 \mathrm{~s}$, however the temperature plateaus at $550^{\circ} \mathrm{C}$ and $750^{\circ} \mathrm{C}$ are not any more clearly visible. This moving average could be used but for blazes of characteristic time more long, such in warehouse fire. At last, it is clear that the moving averages at $-5 \mathrm{~min}$ and $-10 \mathrm{~min}$ have no sense for the fire duration of the presented experiment in this study, even if they may be useful for longer duration of fires.

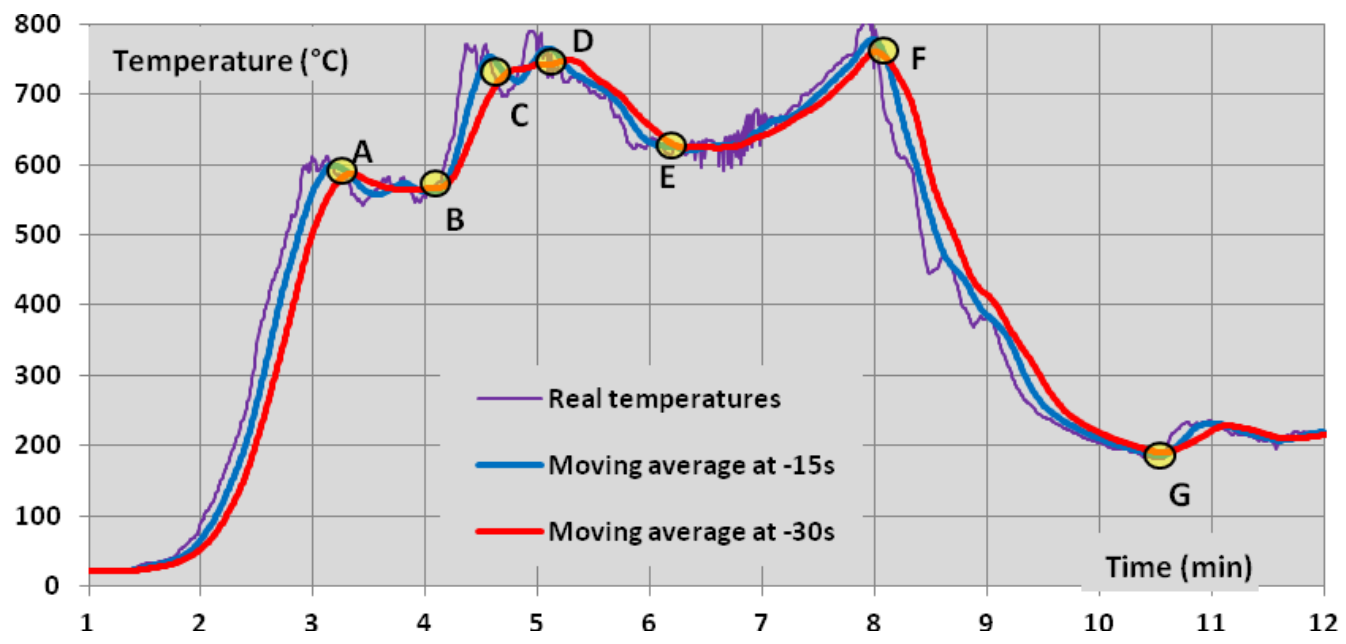

Figure 3. Temperature vs time inside the room on fire close to the door under the ceiling and the two moving averages, at $-15 \mathrm{~s}$ and at $-30 \mathrm{~s}$.



Figure 4. Comparison of different moving averages. 


\section{Conclusion and Application in Decision Support for Fight against Comportment} Fire

As it was reminded in the beginning of this study, fighting against compartment fires may causes many dangers for firefighters, especially backdraft and flashover, which can involve fatal consequences on firefighters. The possibility to detect these dangers as soon as possible can ensure a better security and a better efficiency for the firefighters. This study has allowed to show on one hand that the analysis of the temperature recordings give information about the evolution of the fire and about the efficiency of the applied strategy. And on the other hand it has allowed to show that the use of the comparison of two moving averages centred in the past is useful and may be efficient to detect dangers that may occur, and therefore in order to protect themselves. The comparison between two moving averages centred in the past can be made by the records of the temperatures given by sensors located at strategic locations. Many solutions are available to place these sensors. They can be divided in two categories, either before the intervention on the fire, i.e. during the construction, or during the intervention on the fire.

In the first case when sensors have been placed during the construction, the information can be collected and sent in real time to a control centre and/or to the fire department centre, thus the firefighter commander can have information about the fire before going on site.

During the intervention on the fire, when there are no sensors placed during the construction, other kinds of sensors can be used. Either, sensors may be brought by firemen on the fire suit, or they can place sensors on strategic locations, these sensors being able to give their position and to send information outside to a control centre, especially temperatures.

It is also possible to get information about temperatures using an infrared camera outside. This camera may be placed on the floor or brought by a drone. This last case gives a new possibility to have a look around the fire in order to have a global view of the situation. The whole of these means allows to consider important improvements for the security and for the efficiency of the firefighters in their fight against compartment fires, and consequently a decrease of goods losses and above all human losses.

\section{Acknowledgements}

The authors thank the Paris Fire Brigade (Brigade des Sapeurs-Pompiers de Paris, FRANCE) for its help to carry out the experiments of real fires used for this study.

\section{References}

[1] Svensson, S. (2000) Fire Ventilation. In: Göransson, A.-L., Ed.

[2] Hume, B. (2004) Fire Fighting in Under-Ventilated Compartments: Literature Review. Fire Statistics and Research Division, Office of the Deputy Prime Minister, London.

[3] Ura, F., Kawabata, N. and Tanaka, F. (2014) An Experimental Study on Critical Velocity in Sloping Tunnel with Longitudinal Ventilation under Fire. Fire Safety Journal, 67, 96-106.

[4] Lebey, M., Lambert, E. and Cité, O. (2004) Essai de démonstration de l'efficacité de la ventilation dans les incendies dans un feu d’hôpital, Rapport interne Université du Havre \& Brigade de Sapeurs-Pompiers de Paris.

[5] Lebey, M., Massouh, F., Vidor, R., Le Corre, F., Calas, C. and Ziliox, Cb. (2001) Contrôle des mouvements de fumées dans une station de métro lors d'un feu de rame de rame dans l’un des tunnels, Rapport interne, Université du Havre, ENSAM Paris-Tech, RATP \& Brigade de Sapeurs-Pompiers de Paris.

[6] Jeong, K., Koo, C., and Hong, T. (2014) An Estimation Model for Determining the Annual Energy Cost Budget in Educational Facilities Using SARIMA (Seasonal Autoregressive Integrated Moving Average) and ANN (Artificial Neural Network). Department of Architectural Engineering, Yonsei University, Seoul, Republic of Korea, Energy, 71.

[7] Lee, Y.-S. and Tong, L.-I. (2011) Forecasting Time Series Using a Methodology Based on Autoregressive Integrated Moving Average and Genetic Programming. Department of Industrial Engineering and Management, National Chiao Tung University, 1001, Ta-Hsuch Rd., Hsinchu 300, Taiwan, Knowledge-Based Systems, 24, 66-72.

[8] Pal, A., Singh, J.P. and Dutta, P. (2013) The Path Length Prediction of MANET Using Moving Average Model. International Conference on Computational Intelligence: Modeling Techniques and Applications (CIMTA) 2013, Procedia Technology, 10, 882-889. 